\title{
BMJ Open Prevalence and correlates of smoking and nicotine dependence: results of a nationwide cross-sectional survey among Singapore residents
}

Shazana Shahwan (D) , Edimansyah Abdin, ${ }^{1}$ Saleha Shafie, ${ }^{1}$ Sherilyn Chang, ${ }^{1}$ Rajeswari Sambasivam, ${ }^{1}$ Yunjue Zhang, ${ }^{1}$ Janhavi Ajit Vaingankar, ${ }^{1}$ Yik Ying Teo, ${ }^{2}$ Derrick Heng, ${ }^{3}$ Siow Ann Chong, ${ }^{1}$ Mythily Subramaniam ${ }^{1}$
To cite: Shahwan S, Abdin E, Shafie S, et al. Prevalence and correlates of smoking and nicotine dependence: results of a nationwide crosssectional survey among Singapore residents. BMJ Open 2019;9:e032198. doi:10.1136/ bmjopen-2019-032198

- Prepublication history and additional material for this paper are available online. To view these files, please visit the journal online (http://dx.doi. org/10.1136/bmjopen-2019032198).

Received 07 June 2019 Revised 23 August 2019 Accepted 19 September 2019

Check for updates

(C) Author(s) (or their employer(s)) 2019. Re-use permitted under CC BY-NC. No commercial re-use. See rights and permissions. Published by BMJ.

${ }^{1}$ Research Division, Institute of Mental Health, Singapore, Singapore

${ }^{2}$ Saw Swee Hock School of Public Health, National University of Singapore, Singapore, Singapore

${ }^{3}$ Epidemiology \& Disease Control Division, Ministry of Health, Government of Singapore, Singapore, Singapore

Correspondence to Ms Shazana Shahwan; Shazana_MOHAMED_ SHAHWAN@imh.com.sg

\section{ABSTRACT}

Background Since the Singapore Mental Health Study in 2010 which reported a $16.0 \%$ prevalence rate for current smokers and $4.5 \%$ for nicotine dependence, new antismoking strategies have been implemented. The aim of this study was to compare smoking trends from the 2010 study with the second Singapore Mental Health Study in 2016 (SMHS 2016).

Methods A survey of 6126 individuals aged 18 years and above randomly selected among Singapore residents was conducted using the same methodology as the 2010 study. The measures used in this analysis were sociodemographic questions, the Composite International Diagnostic Interview which assessed for psychiatric disorders, the Fagerstrom Test for Nicotine Dependence and a list of chronic physical conditions that were prevalent in Singapore. Logistic regression analyses were used to test for associations between smoking/nicotinedependence and other measures.

Results In the SMHS 2016, 16.1\% were current smokers and $3.3 \%$ were nicotine-dependent. As compared with non-smokers, current smokers were more likely to be younger, male gender, of ethnic minority and had lower/ vocational education level. Younger age, male gender, lower/vocational education and psychiatric disorders (major depression, bipolar disorder and alcohol use disorders) predicted nicotine dependence. No associations were found between nicotine dependence and any of the chronic conditions.

Conclusion The prevalence of current smokers in the population has plateaued while that of nicotine dependence has decreased from 2010. However, the study did not investigate the use of e-cigarettes. Inequalities in smoking and nicotine dependence continue to pervade the population particularly among those of ethnic minority, lower/vocational education and the mentally ill.

\section{INTRODUCTION}

Cigarette smoking is a leading cause of preventable death worldwide. ${ }^{1}$ Smoking-related diseases contribute significantly to the global rise in incidence of non-communicable diseases in both developed and developing countries. ${ }^{2}$ Smoking ranks high among
Strengths and limitations of this study

- The study reports the prevalence and correlates of smoking and nicotine dependence based on a large representative sample of the Singapore population.

- The same methodology and instruments employed in the 2010 study was applied allowing direct comparisons with the earlier study.

- The study did not include individuals below 18 years of age and did not assess for alternative forms of smoking such as e-cigarettes that are gaining popularity.

- Reliance on self-report could lead to an underestimation of the true prevalence of nicotine dependence and associations with mental and medical conditions.

public health problems in the world, with an estimated 7.4-9.7 million tobacco-attributable deaths by $2030 .^{3}$

In 2003, the World Health Assembly adopted the Framework Convention on Tobacco Control (FCTC) to take steps to reduce both the supply of and demand for tobacco products. This treaty is now ratified by 181 countries. $^{2}$ To help those countries fulfil their commitment to the FCTC, the WHO disseminated recommendations consisting of six strategies: monitor tobacco use; protect people from tobacco smoke; offer help to quit tobacco use; warn about the dangers of tobacco; enforce bans on tobacco advertising, promotion and sponsorship; and raise taxes on tobacco. Steady decline in smoking prevalence rates has been witnessed in countries such as New Zealand, ${ }^{4}$ Turkey and Sweden ${ }^{5}$ since the implementation of FCTC strategies.

However, these changes have not occurred uniformly across all population groups. An upward trend in smoking debut in early adolescence was found in a European study. ${ }^{6}$ 
Disparities in smoking prevalence in underprivileged populations are also widening. In the USA, for example, less than $20 \%$ of those at or above the poverty level smoke compared with $30 \%$ of those below the poverty level. Other socioeconomic measures associated with inequalities in smoking include education, income and neighbourhood deprivation. ${ }^{7}$ The higher prevalence of smoking in individuals from lower socioeconomic status (SES) groups is the single most important cause of socioeconomic differences in mortality. ${ }^{8}$

Another subpopulation with exceptionally high rates of smoking internationally is individuals with mental illness. Individuals with mental illness smoke at rates approximately twice that of adults without mental disorders. ${ }^{9}$ Smoking is believed to account for the majority of excess mortality among individuals with serious mental illness. ${ }^{10}$ Life expectancy among people with severe mental illness is 25 years less than that among the general population. ${ }^{11}$ Monitoring trends in the population and between subgroups aid countries in taking necessary corrections or new actions for tobacco control.

Singapore is a city-state located in Southeast Asia with a multi-ethnic population and was among the first 40 countries to ratify the FCTC. It exercises stringent smoking policies and extensive regulations on the demand and supply of tobacco. ${ }^{12}$ In the nationwide Singapore Mental Health Study conducted in 2010 (SMHS 2010), Picco and colleagues $^{13}$ reported local smoking prevalence rates of $16 \%$. Smokers were more likely to be of younger age, male gender, Malay ethnicity and have lower education. Prevalence of nicotine dependence was higher in those with alcohol abuse and those experiencing chronic pain. Singapore aims to lower smoking prevalence rates to $12 \%$ by 2020 through a multipronged strategy composed of preventing initiation among the youth, public education and specific programmes for target groups, and providing more support and access to smoking cessation programmes. ${ }^{14}$

The purpose of this study was to compare and contrast smoking trends from the 2010 study with the second Singapore Mental Health Study which began in 2016 (SMHS 2016). ${ }^{15}$ As stricter anti-smoking laws (e.g., raising minimum smoking age to 21 years, expanding smoke-free zones) and new campaigns were launched after 2010, we hypothesise that there will be a decline in the prevalence of smoking and nicotine dependence in the SMHS 2016. This study also examined sociodemographic risk factors of smoking and nicotine dependence as well as the association of nicotine dependence with lifetime psychiatric and physical disorders.

\section{METHODS}

\section{Participants and procedure}

The SMHS 2016 was conducted between 2016 and 2018 following the same procedures as the SMHS $2010 .{ }^{16}$ This population-based, cross-sectional study included Singapore citizens and permanent residents aged 18 years and above living in Singapore. The sampling frame was based on a national population registry of all citizens and permanent residents in Singapore, and is updated regularly. Individuals were randomly selected using a disproportionate stratified sampling design with 16 strata defined according to ethnicity (Chinese, Malay, Indian, Others) and age groups (18-34, 35-49, 50-64, 65 and above). Residents aged 65 and above, Malays, and Indians were over sampled to ensure that an adequate sample size would be achieved to improve the reliability of estimates for the subgroup analysis. We requested 15907 records of Singapore residents. 11100 records were eventually released in eight different batches. About 20\% of these were ineligible cases (e.g., ineligible language, incorrect address) which were excluded from the response rate calculation. In all, 6126 respondents were interviewed, giving a response rate of $69.5 \%$. Data on household structure were not collated and not accounted for in the analysis.

An invitation letter was sent to each respondent followed by a personal home visit by a trained interviewer to obtain his/her agreement to participate in the survey. Trained interviewers from a survey research company conducted face-to-face interviews with those who agreed to participate in the study. The questionnaires were available in English, Chinese and Malay. Residents who were incapable of doing an interview due to severe physical/ mental conditions, language barriers; were living outside the country, institutionalised/hospitalised and those who were not contactable due to incomplete/incorrect address were excluded from the survey. Consent was obtained from all participants prior to commencement of any study procedure. Parental consent was also obtained for minors aged $18-20$ years.

\section{MEASURES}

\section{Sociodemographic information}

Data on gender, age groups (18-34, 35-49, 50-64 and $\geq 65$ years), ethnicity (Chinese, Malay, Indian and Others), marital status (single, married, divorced/separated or widowed), educational level (primary and below, secondary, vocational institute, pre-university/junior college, diploma and university), employment status (employed, unemployed and economically inactive) and household income were collected.

\section{Psychiatric disorders}

The WHO World Mental Health Composite International Diagnostic Interview is a structured instrument used to generate diagnoses of Diagnostic and Statistical Manual of Mental Disorders, 4th Edition (DSM-IV) disorders using established algorithms with organic exclusion criteria and hierarchical rules. Modules on depression, mania, generalised anxiety disorder, obsessive compulsive disorder $(\mathrm{OCD})$ and alcohol use were included in the survey.

\section{Smoking and nicotine dependence}

Information on smoking was collected through a question that asked participants whether they were current 
smokers, ex-smokers or non-smokers who never smoked before. The 6-item Fagerstrom Test for Nicotine Dependence was used to assess physical dependence on tobacco smoking. Scores of 4 or less are classified as low dependence while scores of 8 to 10 , as very high dependence. We categorised those with scores five and above as dependence as defined by previous studies, ${ }^{17}$ including our previous study ${ }^{13}$ to ensure consistency for comparison.

\section{Chronic medical conditions}

Respondents were asked to report whether 'a doctor ever told you that you have any of the following...' This was followed by a list of 18 chronic medical conditions that are prevalent in Singapore in the form of a checklist. These disorders were reclassified into the following nine types of physical disorders: hypertension, hyperlipidemia, diabetes, asthma, chronic pain, cardiovascular diseases, ulcers, thyroid problems and cancer.

\section{Statistical analysis}

All estimates were weighted to adjust for over-sampling and post-stratified for age and ethnicity distributions between the survey sample and the Singapore resident population. Mean and SD were calculated for continuous variables, and frequencies and percentages for categorical variables. The sociodemographic characteristics were compared among the groups and tested for significant differences using $\chi^{2}$ tests. This was followed by multiple logistic regression and multinomial logistic regression analyses to explore the sociodemographic correlates of nicotine dependence, and current or ex-smoking status. Gender-specific analyses were also conducted to compare the prevalence rates between 2010 and 2016 as well to explore sociodemographic correlates of nicotine dependence, current and ex-smoking status. Statistical significance was evaluated at the $<0.05$ level using two-sided tests. All statistical analyses were carried out using the Statistical Analysis Software System V.9.

\section{Patient and public involvement}

This research was done without patient involvement. Patients were not invited to comment on the study design and were not consulted to develop patient relevant outcomes or interpret the results. Patients were not invited to contribute to the writing or editing of this document for readability or accuracy.

\section{RESULTS}

\section{Prevalence of smoking and nicotine dependence}

Table 1 shows the sociodemographic characteristics of the sample classified by smoker, ex-smoker and non-smoker status. Table 2 summarises the prevalence rates in 2010 and 2016. Among the population, $16.1 \%$ were current smokers, $10.5 \%$ were ex-smokers, while $3.3 \%$ had nicotine dependence. The prevalence of smokers among men was $27.1 \%$ and among women it was $5.3 \%$. Online supplementary table 1 provides further information of the prevalence of current smokers, ex-smokers and nicotine dependence by age group and gender.

\section{Sociodemographic correlates of nicotine dependence}

Table 3 shows the sociodemographic correlates of current smokers and ex-smokers. As compared with non-smokers, those who were current smokers were more likely to be of Malay, Indian or Other ethnicity (vs Chinese), male gender, divorced/separated (compared with married), have lower education level (i.e., primary or secondary education) or vocational qualifications (i.e., polytechnic or technical education) (compared with university degree). Those in the older age groups $(\geq 50$ years compared with 18-34 years), economically inactive (compared with employed) and with a monthly household income of more than SGD 10, 000 (compared with a monthly household income of SGD 2000) were less likely to be a current smoker. Compared with non-smokers, ex-smokers, similarly, were of Malay or other ethnicity, male gender, divorced/separated and had lower/vocational education level. Online supplementary table 2a,b present the sociodemographic correlates of current and ex-smokers of men and women, respectively. The results are consistent for both sexes with exception to income, where the highest income group (SGD 10, 000 and above) was associated with lower odds of smoking in men, whereas the lower income group (SGD 2000-3999) was associated with lower odds of smoking in women. The relationship between marital status and smoking however was inconsistent with no association found for men and a lower odds of current smoking associated with being widowed in women (although being divorced/separated was associated with higher odds of being a current or ex-smoker for the overall sample).

Multiple logistic regression showed (table 4) that men had seven times higher risk of nicotine dependence than women. Furthermore, nicotine dependence was significantly higher in those with lower or vocational educational qualifications (compared with university education). Older age ( $\geq 50$ years, compared with $18-34$ years), being economically inactive (compared with employed) and monthly household income of SGD 4000-5999 (compared with less than SGD 2000) was associated with lower risk of nicotine dependence. Online supplementary table $3 \mathrm{a}$,b present the sociodemographic correlates of nicotine dependence in men and women, respectively. The results for both sexes are consistent with that of the overall sample.

\section{Relationship between nicotine dependence and psychiatric and physical disorders}

Those with nicotine dependence were significantly more likely to have major depressive disorder (MDD), bipolar disorder, alcohol abuse and alcohol dependence. Gender difference was observed for OCD where women with nicotine dependence were six times more likely to have OCD than those without nicotine dependence but this 
Table 1 Sociodemographic profile of the sample by smoking status

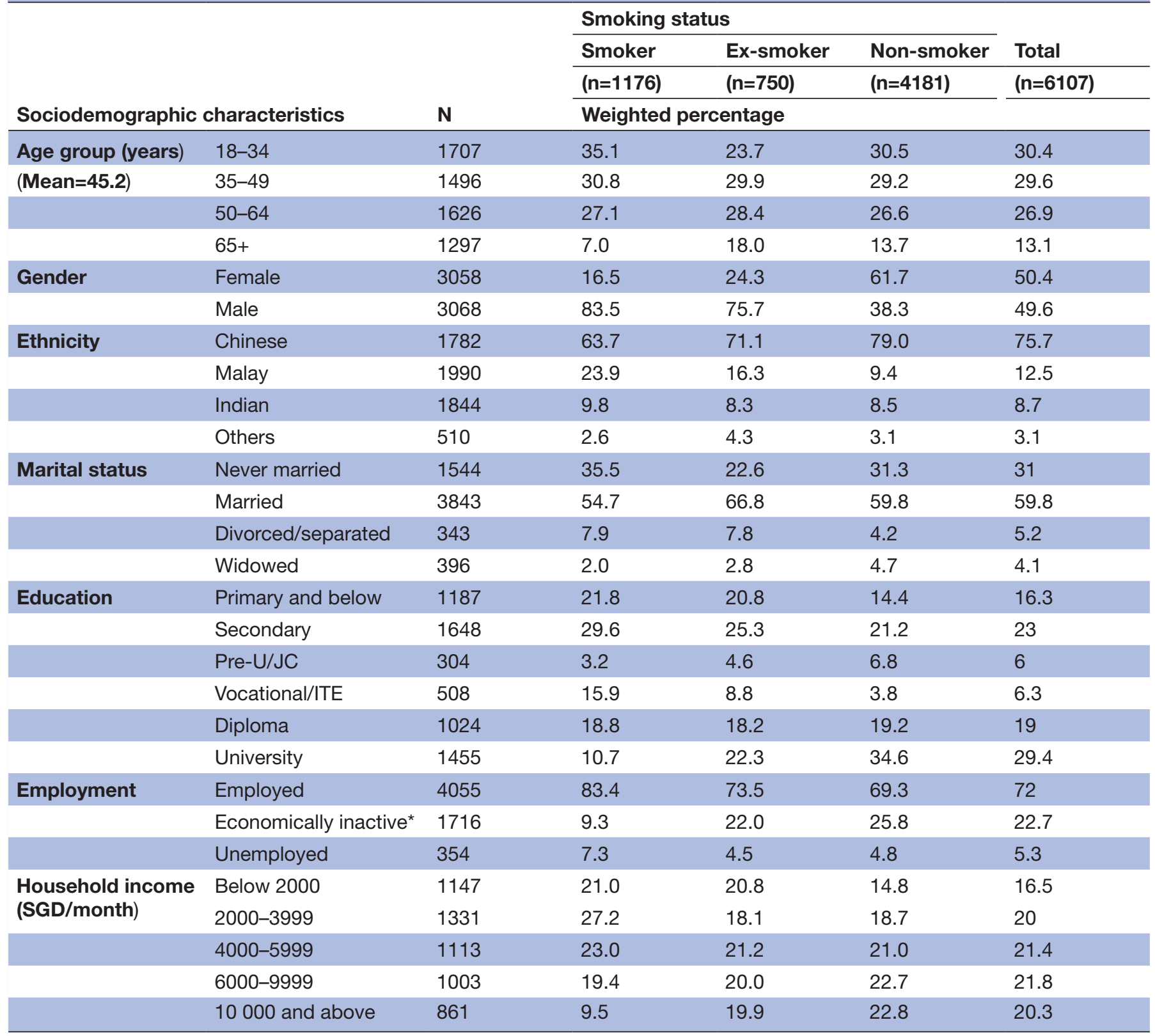

*Includes homemakers, students and retirees/pensioners.

ITE, Institute of Technical Education; JC, Junior College; Pre-U, Pre-University; SGD, Singapore dollars.

Table 2 Prevalence of Current smokers, Ex-smokers and Nicotine dependence in SMHS 2010 and SMHS 2016

\begin{tabular}{lrrl}
\hline & $\mathbf{2 0 1 0}$ & $\mathbf{2 0 1 6}$ & $\mathbf{P}$ value \\
\hline Current smokers & 16.0 & 16.1 & n.s. \\
Male & 27.0 & 27.1 & n.s. \\
Female & 5.6 & 5.3 & n.s. \\
Ex-smokers & 10.8 & 10.5 & n.s. \\
$\begin{array}{l}\text { Nicotine } \\
\text { dependence }\end{array}$ & 4.5 & 3.3 & 0.007 \\
\hline
\end{tabular}

$\chi^{2}$ analysis.

n.s., not statistically significant; SMHS, Singapore Mental Health Study. association was not observed in men. These results are summarised in table 5 .

No associations were found between nicotine dependence and any of the chronic conditions.

\section{DISCUSSION}

The prevalence of smoking in the general population remained at $16 \%$ from our 2010 national survey. ${ }^{13}$ Prevalence rates in men and women, likewise, remained at about $27 \%$ in men and about $5 \%$ in women indicating a plateau in smoking prevalence. The sharpest decline occurred between the 1980 s and the $2000 \mathrm{~s}^{18}$ with local rates hovering around $15 \%$ in the past 10 years. ${ }^{13}$ However, 
Table 3 Sociodemographic correlates of Current smokers and Ex-smokers

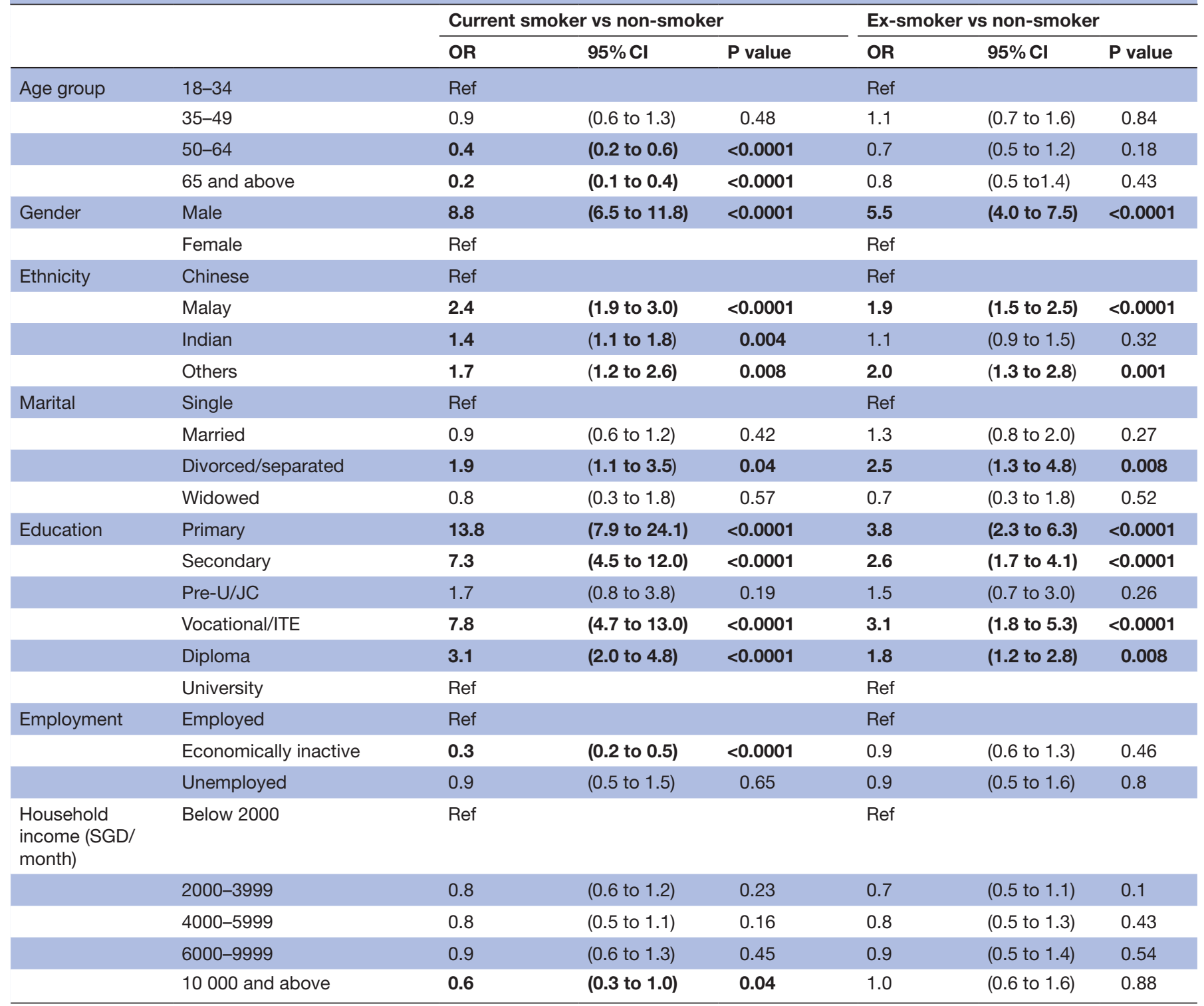

Multinomial logistic regression analysis controlled for potential confounders including age, ethnicity, marital status, education, employment and household income.

ITE, Institute of Technical Education; JC, junior college; Pre-U, Pre-University; SGD, Singapore dollars.

a desirable shift in nicotine dependence from $4.5 \%$ in 2010 to $3.3 \%$ in 2016 was observed. With one of the lowest smoking prevalence rates in the world, Singapore's challenge is to go beyond these rates to achieve the target set at $12 \%$ by $2020 .{ }^{12}$ Novel endgame solutions such as prohibiting the sales of tobacco to citizens born after year 2000 and using plain packaging have been proposed. ${ }^{19}$

It was noteworthy that as many as one in four adult men are current smokers accounting for the vast majority of smokers in the country, with men being seven times more likely than women to be nicotine-dependent. More recently, Subramaniam and colleagues ${ }^{20}$ through focus group discussions with Singaporean youths identified multiple personal (e.g., coping), social (e.g., for networking) and familial influences (e.g., early exposure) on young adults' smoking behaviours which provide actionable information for further anti-smoking initiatives. Factors such as traditional values, normative gender expectations and economic independence have been purported for the wide margin of difference between the sexes. $^{21}$

Not surprisingly, smoking and nicotine dependence groups were over-represented in those with lower or vocational qualifications and less likely to be associated with higher income. Marques-Vidal and colleagues ${ }^{22}$ suggested that those with higher levels of education are more responsive to social initiatives to cut down smoking and anti-smoking messages or have more contact with exemplary role models. Despite the rising cigarette prices/taxes with the average cost of a pack of 20 cigarettes priced at US\$9.66 (SGD\$13.31), ${ }^{23}$ higher levels of smoking and nicotine dependence were observed among 
Table 4 Sociodemographic correlates of nicotine dependence

\begin{tabular}{|c|c|c|c|c|}
\hline & & OR & $95 \% \mathrm{Cl}$ & $P$ value \\
\hline \multirow[t]{4}{*}{ Age group } & $18-34$ & Ref & & \\
\hline & $35-49$ & 0.6 & (0.3 to 1.1$)$ & 0.34 \\
\hline & $50-64$ & 0.3 & (0.2 to 0.6$)$ & 0.001 \\
\hline & 65 and above & 0.3 & (0.1 to 0.7$)$ & 0.007 \\
\hline \multirow[t]{2}{*}{ Gender } & Male & 6.9 & (3.6 to 13.2$)$ & $<0.0001$ \\
\hline & Female & Ref & & \\
\hline \multirow[t]{4}{*}{ Ethnicity } & Chinese & Ref & & \\
\hline & Malay & 1.5 & (0.9 to 2.3 ) & 0.1 \\
\hline & Indian & 1.3 & (0.8 to 2.0$)$ & 0.31 \\
\hline & Others & 1.4 & (0.6 to 3.2$)$ & 0.41 \\
\hline \multirow[t]{4}{*}{ Marital } & Single & Ref & & \\
\hline & Married & 0.8 & (0.5 to 1.5$)$ & 0.5 \\
\hline & Divorced/separated & 0.8 & (0.3 to 1.8$)$ & 0.57 \\
\hline & Widowed & 1.7 & (0.4 to 6.7$)$ & 0.43 \\
\hline \multirow[t]{6}{*}{ Education } & Primary & 37.0 & (8.3 to 165.1 ) & $<0.0001$ \\
\hline & Secondary & 23.3 & (5.8 to 92.6$)$ & $<0.0001$ \\
\hline & Pre-U/JC & 2.1 & (0.4 to 9.8 ) & 0.359 \\
\hline & Vocational/ITE & 16.0 & (4.0 to 63.8$)$ & $<0.0001$ \\
\hline & Diploma & 10.0 & (2.7 to 37.0$)$ & $<0.0001$ \\
\hline & University & Ref & & \\
\hline \multirow[t]{3}{*}{ Employment } & Employed & Ref & & \\
\hline & Economically inactive & 0.1 & (0.1 to 0.3 ) & $<0.0001$ \\
\hline & Unemployed & 0.6 & (0.3 to 1.4$)$ & 0.26 \\
\hline \multirow{5}{*}{$\begin{array}{l}\text { Household income } \\
\text { (SGD/month) }\end{array}$} & Below 2000 & Ref & & \\
\hline & 2000-3900 & 0.8 & (0.5 to 1.5$)$ & 0.56 \\
\hline & $4000-5999$ & 0.4 & (0.2 to 0.8$)$ & 0.009 \\
\hline & 6000-9999 & 0.6 & (0.3 to 1.4$)$ & 0.24 \\
\hline & 10000 and above & 0.6 & (0.2 to 1.4 ) & 0.21 \\
\hline
\end{tabular}

ITE, Institute of Technical Education; JC, Junior College; Pre-U, Pre-University; SGD, Singapore dollars.

those with the lowest income levels suggesting alternative strategies are needed to reduce morbidity and mortality due to smoking for this group.

Two other sociodemographic factors that were associated with current smoking prevalence were age and ethnic minority status (Malay and Others ethnic groups). An age effect was observed with the prevalence of smoking being higher in the younger age groups despite the combined efforts of raising the minimum age for smoking, increasing cigarette prices and smoking prevention and cessation programmes in institutes of higher learning in the recent years. Shahwan and colleagues ${ }^{24}$ through focus group discussions with youths identified various elements that were deemed to be efficacious in anti-smoking campaigns (e.g., positive tone, low-fear visual images, low 'controlling' language) which may be translated into continued efforts towards further reducing smoking rates in youths. With regard to ethnicity, almost all Malays in
Singapore are Muslims. While drinking alcohol is clearly forbidden in Islam, smoking is deemed by many Muslims as acceptable. Ethnic differences may also represent residual confounding by socioeconomic influences that have not been adequately controlled using our proxy measures.

The correlates of smoking and nicotine dependence identified in this study (i.e., the association between smoking and younger age, male gender, ethnic minority, lower/vocational education) are similar to the findings of the 2010 study, representing the stability and persistence of these factors.

The relationship between being economically inactive and smoking is less clear. While unemployment is defined as being out of work and actively seeking work, economic inactivity exists when a person is without any form of employment and is not actively seeking work. The majority of individuals in the economic inactivity group 
Table 5 Prevalence and OR of other lifetime psychiatric disorders in people with nicotine dependence

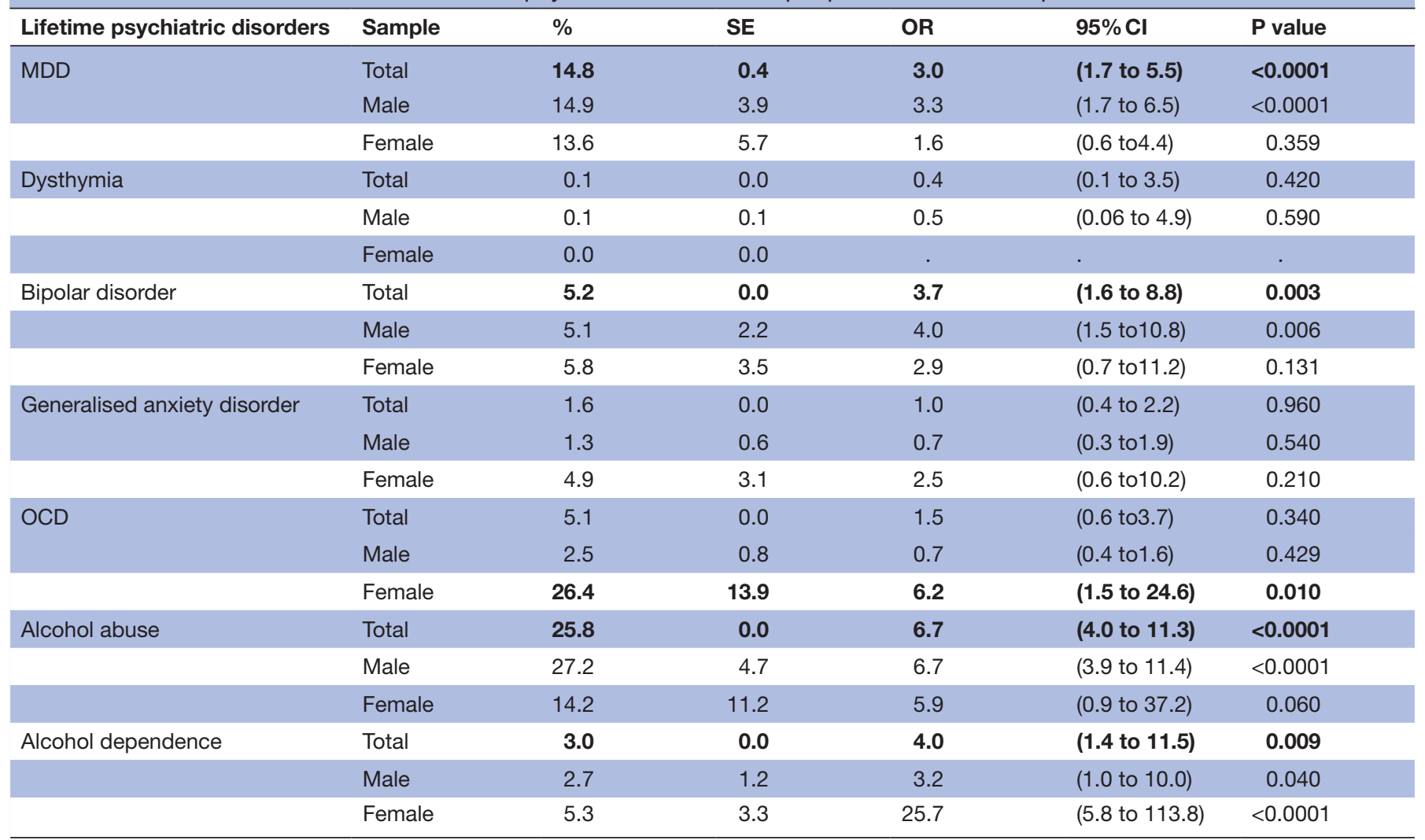

Multiple logistic regression analyses in total sample and by gender specification, adjusted for age.

MDD, major depressive disorder; OCD, obsessive compulsive disorder; SE, standard error.

consist of housewives, retirees and students. As such, we speculate that there were several protective factors against smoking for this group such as higher education, spousal support, increasing health concerns with advancing age and the desire to improve longevity and quality of life.

Nicotine dependence was significantly associated with alcohol abuse as well as alcohol dependence. Nicotine-dependent individuals were about seven times more likely to abuse alcohol and four times more likely to be dependent on alcohol than those who were non-nicotine dependent. Psychosocial factors, such as risk-prone personality traits, greater opportunities and inclinations to drink, have been widely accepted as reasons for the well-documented link between smoking and alcoholism. ${ }^{25}$ However, these psychosocial factors may not completely account for the association between smoking and alcohol problems. Some authors have speculated that the progression from the use of alcohol and tobacco to abuse may be facilitated by effects of early-stage use on central reward circuitry. ${ }^{26}$

An association between nicotine dependence and MDD and bipolar disorder, which was not apparent in 2010 , emerged in this study. The proportion of individuals with nicotine dependence who had MDD and bipolar disorder increased from $7 \%$ to $14 \%$ and $1 \%$ to $5 \%$, respectively. The prevalence of nicotine dependence in patients with mood disorders has been reported to range from $50 \%$ to $70 \%$ compared with $25 \%$ in the general population in other studies. ${ }^{27}$ The comorbidity between nicotine dependence and mood disorders may be explained in at least two ways. First, various studies have demonstrated shared genetic and environmental influences. Second, it could also be argued that (i) depression increases the risks of smoking (i.e., through self-medication) or (ii) smoking increases the risk of depression. ${ }^{28}$ Given that the proportion of MDD and bipolar disorder among individuals with nicotine dependence increased from 2010 to 2016, further exploration of this relationship is warranted.

A gender difference was found in the association between nicotine dependence and OCD where $26.4 \%$ of women with nicotine dependence had OCD compared with $2.5 \%$ for men. We identified three other studies that have similarly found an association between smoking and OCD only in women. ${ }^{29-31}$ However, our finding differs from the vast majority of clinical studies that have shown that patients with OCD are less likely to smoke compared with the general population. ${ }^{32}{ }^{33}$ As suggested by $\mathrm{Wu}$ and colleagues, this may have to do with differences between clinical and community samples and further research is needed to shed light on the association between nicotine dependence and OCD in men and women.

Current population-level tobacco control interventions may be less effective for those with mental illness. Health promotion campaigns and smoking policies that use stigma (e.g., the peril that smokers bring to the rest of the population) as the main motivating factor for giving up smoking may contribute to social isolation among those 
with psychiatric disorders. ${ }^{34}$ Thus, these efforts are more likely to perpetuate smoking inequalities than remove them. Cook and colleagues ${ }^{35}$ found that individuals receiving mental health treatment are not only less likely to smoke but are more likely to quit, suggesting that the mental health facility is a promising setting to promote smoking cessation in this group.

The study had several limitations. We did not include individuals below 18 years of age and did not assess other forms of smoking such as use of e-cigarettes which is gaining popularity despite its ban in Singapore. Second, we relied on self-report which could lead to an underestimation of true prevalence of nicotine dependence and associations with mental and medical conditions. Third, as this was a cross-sectional study, we are unable to determine causality. Fourth, although we achieved a fair response rate of $69.5 \%$, there were sociodemographic differences between respondent and non-respondent groups. Respondents were more likely to be in the younger age group (ie, 18-35 years compared with $35-49$ years; OR $=0.65, \mathrm{p}<0.0001 ; 50-64$ years; $\mathrm{OR}=0.68, \mathrm{p}<0.0001 ; 65$ +years; $\mathrm{OR}=0.82, \mathrm{p}=0.005$ ) and of Malay or Indian ethnicity (compared with Chinese; $\mathrm{OR}=1.87, \mathrm{p}<0.0001$ and $\mathrm{OR}=1.91, \mathrm{p}<0.0001$, respectively). This could lead to obscuring true prevalence as mental health determinants differ between responders and non-responders. ${ }^{36}$ In order to minimise the impact of this bias, non-response weighting was used to statistically adjust for these differences. The strengths of this study include the large sample size, the use of structured, well-validated instruments and a methodology similar to the 2010 study that allows for a direct comparison between these two time points.

Acknowledgements We would like to thank the interviewers who collected the data for the study.

Contributors SAC, MS and JAV were involved in the planning of the study and provided advice and guidance throughout the conduct study, and manuscript writing. ShS, SaS, SC, RS and YZ were involved in the conduct of the study. EA conducted the statistical analyses. DH and YYT provided expert opinion. All authors reviewed the final document.

Funding The study was funded by the Ministry of Health Singapore and Temasek Foundation Innovates.

Competing interests None declared.

Patient consent for publication Not required.

Provenance and peer review Not commissioned; externally peer reviewed.

Data availability statement № data are available.

Open access This is an open access article distributed in accordance with the Creative Commons Attribution Non Commercial (CC BY-NC 4.0) license, which permits others to distribute, remix, adapt, build upon this work non-commercially, and license their derivative works on different terms, provided the original work is properly cited, appropriate credit is given, any changes made indicated, and the use is non-commercial. See: http://creativecommons.org/licenses/by-nc/4.0/.

ORCID iD

Shazana Shahwan http://orcid.org/0000-0003-4584-0751

\section{REFERENCES}

1 Méndez D, Alshanqeety O, Warner KE. The potential impact of smoking control policies on future global smoking trends. Tob Control 2013;22:46-51.
2 WHO. Who / parties to the who framework convention on tobacco control, 2017. Available: https://www.who.int/fctc/signatories_ parties/en/

3 Mathers CD, Loncar D. Projections of global mortality and burden of disease from 2002 to 2030. PLoS Med 2006;3:e442.

$4 \mathrm{Ng} \mathrm{M}$, Freeman MK, Fleming TD, et al. Smoking prevalence and cigarette consumption in 187 countries, 1980-2012. JAMA 2014;311.

5 Bilano V, Gilmour S, Moffiet T, et al. Global trends and projections for tobacco use, 1990-2025: an analysis of smoking indicators from the who comprehensive information systems for tobacco control. The Lancet 2015;385:966-76.

6 Marcon A, Pesce G, Calciano L, et al. Trends in smoking initiation in Europe over 40 years: a retrospective cohort study. PLoS One 2018;13:e0201881.

7 Hill S, Amos A, Clifford D, et al. Impact of tobacco control interventions on socioeconomic inequalities in smoking: review of the evidence. Tob Control 2014;23:e89-97.

8 Stringhini Set al. Association of socioeconomic position with health behaviors and mortality. JAMA 2010;303.

9 Lasser K, Boyd JW, Woolhandler S, et al. Smoking and mental illness: a population-based prevalence study. JAMA 2000;284:2606-10.

10 Campion J, Checinski K, Nurse J, et al. Smoking by people with mental illness and benefits of smoke-free mental health services. Adv. psychiatr. treat 2008;14:217-28.

11 Kessler RC, Chiu WT, Demler O, et al. Prevalence, severity, and comorbidity of 12-month DSM-IV disorders in the National comorbidity survey replication. Arch Gen Psychiatry 2005;62:617.

12 Amul GGH, Pangestu Pang T. Progress in tobacco control in Singapore: lessons and challenges in the implementation of the framework convention on tobacco control. Asia Pac Policy Stud 2018;5:102-21.

13 Picco L, Subramaniam M, Abdin E, et al. Smoking and nicotine dependence in Singapore: findings from a cross-sectional epidemiological study. Ann Acad Med Singapore 2012;41:325-34.

14 Health Promotion Board. Health promotion board unveils twopronged strategy to step up tobacco control efforts on world no tobacco day, 20141-4. Available: https://www.hpb.gov.sg/article/ health-promotion-board-unveils-two-pronged-strategy-to-step-uptobacco-control-efforts-on-world-no-tobacco-day

15 Subramaniam M, Abdin E, Vaingankar JA, et al. Tracking the mental health of a nation: prevalence and correlates of mental disorders in the second Singapore mental health study. Epidemiol Psychiatr Sci 2019;32:1-10.

16 Subramaniam M, Vaingankar J, Heng D, et al. The Singapore mental health study: an overview of the methodology. Int $J$ Methods Psychiatr Res 2012;21:149-57.

17 Manimunda SP, Benegal V, Sugunan AP, et al. Tobacco use and nicotine dependency in a cross-sectional representative sample of 18,018 individuals in Andaman and Nicobar Islands, India. BMC Public Health 2012;12:515.

18 Lim SS, Vos T, Flaxman AD, et al. A comparative risk assessment of burden of disease and injury attributable to 67 risk factors and risk factor clusters in 21 regions, 1990-2010: a systematic analysis for the global burden of disease study 2010. The Lancet 2012;380:2224-60.

19 Chia KS. TODAYonline | Singapore should aim to be smoke-free, not just smoke-lite. TODAYonline, 2017. Available: https://www. todayonline.com/commentary/singapore-should-aim-be-smoke-freenot-just-smoke-lite [Accessed 7 Mar 2019].

20 Subramaniam M, Shahwan S, Fauziana R, et al. Perspectives on smoking initiation and maintenance: a qualitative exploration among Singapore youth. Int J Environ Res Public Health 2015;12:8956-70.

21 Pierce JP, White VM, Emery SL. What public health strategies are needed to reduce smoking initiation? Tob Control 2012;21:258-64.

22 Marques-Vidal P, Cerveira J, Paccaud F, et al. Smoking trends in Switzerland, 1992-2007: a time for optimism? J Epidemiol Community Heal 2011;65:281-6.

23 Lim J-L. How much does smoking cost in Singapore? 2018 Available: https://www.imoney.sg/articles/smoking-cost-singapore/ [Accessed 8 Mar 2019].

24 Shahwan S, Fauziana R, Satghare P, et al. Qualitative study of Singaporean youths' perception of antismoking campaigns: what works and what does not. Tob Control 2016;25:e101-6.

25 Dinn WM, Aycicegi A, Harris CL. Cigarette smoking in a student sample: neurocognitive and clinical correlates. Addict Behav 2004;29:107-26.

26 Doyon WM, Dong Y, Ostroumov A, et al. Nicotine decreases ethanolinduced dopamine signaling and increases self-administration via stress hormones. Neuron 2013;79:530-40. 
27 Glassman AH, Helzer JE, Covey LS, et al. Smoking, smoking cessation, and major depression. JAMA 1990;264:1546-9.

28 Munafò MR, Hitsman B, Rende R, et al. Effects of progression to cigarette smoking on depressed mood in adolescents: evidence from the National longitudinal study of adolescent health. Addiction 2008;103:162-71.

29 Grabe HJ, Meyer C, Hapke U, et al. Lifetime-comorbidity of obsessive-compulsive disorder and subclinical obsessivecompulsive disorder in northern Germany. Eur Arch Psychiatry Clin Neurosci 2001;251:130-5.

30 Wu P, Goodwin RD, Fuller C, et al. The relationship between anxiety disorders and substance use among adolescents in the community: specificity and gender differences. J Youth Adolesc 2010;39:177-88.

31 Dell'Osso B, Nicolini H, Lanzagorta N, et al. Cigarette smoking in patients with obsessive compulsive disorder: a report from the International College of obsessive compulsive spectrum disorders (ICOCS). CNS Spectr 2015;20:469-73.
32 Bejerot S, von Knorring L, Ekselius L. Personality traits and smoking in patients with obsessive-compulsive disorder. Eur Psychiatry 2000;15:395-401.

33 Abramovitch A, Pizzagalli DA, Geller DA, et al. Cigarette smoking in obsessive-compulsive disorder and unaffected parents of OCD patients. European Psychiatry 2015;30:137-44

34 Farrimond HR, Joffe H. Pollution, peril and poverty: a British study of the stigmatization of smokers. J Community Appl Soc Psychol 2006;16:481-91.

35 Cook BL, Wayne GF, Kafali EN, et al. Trends in smoking among adults with mental illness and association between mental health treatment and smoking cessation. JAMA 2014;311.

36 de Winter AF, Oldehinkel AJ, Veenstra R, et al. Evaluation of nonresponse bias in mental health determinants and outcomes in a large sample of pre-adolescents. Eur J Epidemiol 2005;20:173-81. 